\title{
CRESCIMENTO, FOSFATASE ÁCIDA E MICORRIZAÇÃO DE ESPÉCIES ARBÓREAS, EM SOLO DE CERRADO DEGRADADO $\left({ }^{1}\right)$
}

\author{
MÁRCIA HELENA SCABORA $\left({ }^{2}\right)$; KÁTIA LUCIENE MALTONI $\left({ }^{3}\right)$; \\ ANA MARIA RODRIGUES CASSIOLATO $\left(3^{*}\right)$
}

\begin{abstract}
RESUMO
A ocupação do cerrado para aumentar a produção agrícola tem gerado a degradação do solo e uma prática recomendada na revegetação dessas áreas é a introdução de espécies arbóreas. O objetivo do trabalho foi avaliar o crescimento (altura e massa fresca e seca de parte aérea), a atividade da fosfatase ácida foliar e colonização micorrízica de mudas de espécies arbóreas não nativas em solo de cerrado degradado. O trabalho foi desenvolvido em casa de vegetação em Ilha Solteira, empregando solo proveniente de uma área de cerrado degradado em processo de regeneração natural, localizada no município de Três Lagoas (MS). O solo, misturado com areia de rio (4:1), foi fumigado com brometo de metila e distribuído em sacos plásticos $(2,5 \mathrm{~L})$. Para o tratamento com inoculação de FMA, $100 \mathrm{~g}$ de solo inóculo (solo de área de cerrado preservado) foi depositado na superfície, logo após o transplante das mudas. Pelos resultados, Psidium guajava L. e Croton floribundus Spreng, seguidos por Tabebuia chrysotricha (Mart. ex DC) Standl) e Rapanea ferruginea (Ruiz et Pav) Mez., tiveram alta colonização radicular e foram altamente ou muito responsivas à micorrização, sugerindo seu potencial em projetos de revegetação no cerrado brasileiro ou no enriquecimento de áreas degradadas.
\end{abstract}

Palavras-chave: fungos micorrízicos arbusculares, revegetação, dependência micorrízica.

\section{ABSTRACT \\ GROWTH LEAF, ACID PHOSPHATASE ACTIVITY AND MYCORRHIZATION OF TREE SPECIES ON DEGRADED CERRADO SOIL}

The occupation of cerrado areas to increase crop production has resulted in soil degradation and introduction of tree species to revegetated these areas is recommended. The objective of this work was to evaluate the plant growth (height, fresh weight and dry weight of above ground), activity of leaf acid phosphatase and mycorrhizal colonization of tree exotic species seedlings on a degraded cerrado soil. The experiment was carried out in a greenhouse at the UNESP - Univ. Estadual Paulista, Campus of Ilha Solteira, Brazil, using soil collected from cerrado degraded area under natural regeneration process, located at Três Lagoas, State of Mato Grosso do Sul, Brazil. The soil, mixed with river sand (4:1), was fumigated with methyl bromide and placed in plastic bags $(2,5 \mathrm{~L})$. For the treatments with AMF inoculation, $100 \mathrm{~g}$ of inoculum soil (soil from preserved Cerrado area) were placed on the soil surface after seedlings were transferred into the plastic bags. Results showed that Psidium guajava L. and Croton floribundus Spreng, followed by Tabebuia chrysotricha (Mart. ex DC) Standl) and Rapanea ferruginea (Ruiz et Pav) Mez, presented high root colonization and very high or high response to mycorrhization, suggesting their potential for projects of revegetation of the Brazilian cerrado, or enrichment of degraded areas.

Key words: arbuscular mycorrhizal fungi, revegetation, mycorrhizal dependency

$\left({ }^{1}\right)$ Recebido para publicação em 2 de abril de 2007 e aceito em 11 de março de 2010.

$\left({ }^{2}\right)$ Doutoranda em Agronomia, área de concentração em Sistema de Produção, UNESP/ Universidade Estadual Paulista, Campus de Ilha Solteira.

$\left({ }^{3}\right)$ UNESP, Departamento de Fitossanidade, Engenharia Rural e Solos, Avenida Brasil, 56, Caixa Postal 31, 15385-000 Ilha Solteira (SP). E-mail: maltoni@agr.feis.unesp.br, anamaria@bio.feis.unesp.br. $\left(^{*}\right)$ Autora correspondente. 


\section{INTRODUÇÃO}

O Cerrado é o segundo ecossistema brasileiro que mais alterações sofreu com a ocupação humana (EMBrapa, 1999). A mudança na vegetação causa desequilíbrio no ecossistema, e as qualidades intrínsecas da nova vegetação forçosamente influenciarão nos processos físicos, químicos e biológicos do solo. Essas alterações trazem consequências ecológicas e ambientais visíveis, as quais geram ações nos diversos setores da sociedade, visando à preservação e ao desenvolvimento de tecnologias para a revegetação (CARNEIRO et al., 1996).

A revegetação de áreas degradadas é uma prática clássica recomendada para a melhoria das condições do solo. Nesta prática, tanto espécies vegetais nativas como não nativas podem ser utilizadas (Mendes Filho, 2004). Embora seja reconhecido que a revegetação com espécies nativas possa aproveitar polinizadores e dispersores naturais para uma auto-regeneração, o uso de espécies não nativas é aceito quando puderem funcionar como condicionadoras do substrato em locais com baixa produtividade (FARIA e CHADA, 2007).

Em ambientes alterados, a revegetação por ser dificultada quando alguns componentes básicos são seriamente afetados, como: o substrato (ausência de matéria orgânica, solos pobres em nutrientes, compactados etc.), os dispersores (fauna, polinizadores etc.), a fonte de propágulos micorrízicos (presença e qualidade da fonte de propágulos adjacentes às áreas danificadas etc.), os fatores ambientais (umidade, temperatura etc.) e a conformidade do relevo (declividade, bacias hidrográficas etc.) (FARIA e CHADA 2007).

$\mathrm{Na}$ comunidade microbiana do solo, um dos importantes constituintes são os fungos micorrizicos arbusculares (FMA). Os efeitos benéficos das simbioses que podem ser formadas dependem de fatores que atuam direta ou indiretamente sobre os componentes da associação, como o fungo micorrízico, a planta hospedeira e o solo (Moreira e Siqueira, 2006) e por meio da colonização radicular e da produção de micélio externo no solo, possibilitam a ampliação da área de exploração do sistema radicular, facilitando a absorção de nutrientes pelas plantas (SCHERER et al., 2004).

Em comunidades naturais, as plantas hospedeiras são colonizadas logo após a germinação e, frequentemente, são infectadas por mais de uma espécie de FMA. Existem evidências da presença de conexões entre hifas fisiologicamente funcionais, em combinações inter e intraespecíficas entre plantas. Por meio destas conexões ocorrem trocas de fotoassimilados entre plantas hospedeiras (especialmente pioneiras) e as não-hospedeiras (geralmente não pioneiras), diminuindo as diferenças na competição, aumentando a coexistência de diferentes espécies e contribuindo para o aumento na diversidade florística (SANDERS, 1996), fato fundamental na recuperação e sustentabilidade de área degradada.

Dentre os efeitos dos FMA esta a absorção do fósforo e sua disponibilização para as plantas, a qual se deve à capacidade das hifas externas explorarem o solo e acessar o nutriente além da zona de esgotamento ao redor das raízes (JAKOBSEN, 1995). Na planta, a utilização das reservas de fósforo envolve as fosfatases ácidas, sendo sua expressão regulada por diversos fatores ambientais e fisiológicos da planta (Duff et al., 1994). A deficiência de fósforo nas plantas leva ao aumento da atividade dessa enzima no tecido vegetal (GARCIA e ASCENCIO, 1992), e sua alta atividade tem sido relacionada à resposta da planta à deficiência desse nutriente (AsCENCIO, 1994).

As espécies arbóreas estudadas foram observadas crescendo próximo à área de cerrado em questão, sendo algumas recomendadas para reflorestamentos heterogêneos destinados à recomposição de áreas degradadas ou de preservação permanente (LORENZI, 2002). Devido à necessidade de recuperar ou, ao menos, minimizar os efeitos da degradação presente no Bioma Cerrado, é que se propôs o desenvolvimento deste trabalho, que teve o objetivo de avaliar o crescimento, a atividade da fosfatase ácida foliar e colonização micorrízica de mudas de espécies arbóreas não nativas em solo de cerrado degradado.

\section{MATERIAL E MÉTODOS}

O presente trabalho foi desenvolvido em casa de vegetação. O solo, classificado como Latossolo Vermelho Distrófico (EMBrapa, 1999), foi coletado em área de cerrado degradado, em processo de regeneração natural, localizada no Horto Rio Verde, pertencente à International Paper Ltda (latitudes de $20^{\circ} 57^{\prime} 46^{\prime \prime} \mathrm{S}, 52^{\circ} 24^{\prime}$ 03" W), Três Lagoas, MS, em 2000. O experimento foi montado em esquema fatorial $6 \times 2$, sendo 6 espécies arbóreas e 2 tratamentos de inoculação (com e sem) de FMA, com 10 repetições.

A caracterização inicial do solo, de uma amostra composta por 40 amostras simples, coletada na camada de $0-0,10 \mathrm{~m}$, seca à sombra, peneirada (malha de $2 \mathrm{~mm}$ ) e homogeneizada, indicou os seguintes valores: $\mathrm{pH}\left(\mathrm{CaCl}_{2}\right)=4,1 ; \mathrm{MO}=17 \mathrm{~g} \mathrm{dm}^{-3}$; $\mathrm{P}=3 \mathrm{mg} \mathrm{dm}^{-3} ; \mathrm{K}, \mathrm{Ca}, \mathrm{Mg}, \mathrm{H}+\mathrm{Al}$ e $\mathrm{CTC}=0,4 ; 3 ; 1 ; 22,6 \mathrm{e}$ 
$26,7 \mathrm{mmol}_{\mathrm{c}} \mathrm{dm}^{-3}$ respectivamente e $\mathrm{V} \%=18$ (RAIJ e QuAGGIO, 1983).

Outra parte da amostra composta do solo foi utilizada para a determinação do número de esporos dos FMA autóctones. Eles foram contados após o peneiramento úmido de $100 \mathrm{~g}$ de solo (GERDE e Nicolson, 1963) e centrifugação em solução de sacarose (JENKINS, 1964). A contagem foi realizada em placa com anéis concêntricos, sob microscópico estereoscópio. A determinação foi realizada em três amostras de $100 \mathrm{~g}$ de solo.

As espécies arbóreas estudadas foram: Eugenia uniflora L. (pitangueira), Psidium guajava L. (goiabeira), Croton floribundus Spreng (capixingui), Pterigyne nitens Tul (amendoim bravo), Tabebuia chrysotricha (Mart. ex DC) Standl (ipê amarelo) e Rapanea ferruginea (Ruiz et Pav) Mez (pororoca). Para obtenção das mudas, as sementes foram desinfestadas superficialmente com hipoclorito de sódio a $1 \%$, por 2 minutos, e a germinação foi feita em papel de filtro esterilizado, em caixas plásticas, sob condições de laboratório.

Como substrato, utilizou-se solo misturado com areia de rio lavada na proporção 4:1 e fumigado com $263 \mathrm{~cm}^{3}$ de brometo de metila por $\mathrm{m}^{3}$ de substrato seco. As plântulas foram transplantadas para a região central de 20 sacos plásticos por espécie, com capacidade de 2,5 kg de substrato. Destes sacos, 10 foram utilizados para o tratamento com inoculação de FMA e receberam, na superfície, $100 \mathrm{~g}$ de solo inóculo (solo de área de cerrado preservado) contendo cerca de 1816 esporos de FMA da comunidade autóctone (não previamente identificados). Com o objetivo de restabelecer a comunidade microbiana no solo dos tratamentos sem inoculação, foram adicionados 100 $\mathrm{mL}$ do filtrado do solo, empregado com fonte de inóculo de microrganismos, porém sem os propágulos de fungos micorrízicos.

As plantas foram avaliadas para altura aos 180 dias do transplante. Após este período, determinou-se a massa fresca de parte aérea (MFPA) antes de ser colocada em saco de papel, mantida em estufa a $60^{\circ} \mathrm{C}$ até massa constante, e a massa seca de parte da aérea (MSPA).

As raízes foram coletadas, lavadas em água corrente e armazenadas temporariamente em álcool $50 \%$. Posteriormente, um grama de raiz, por repetição, por tratamento, foi clarificada em $\mathrm{KOH} 10 \%$, acidificada com $\mathrm{HCl} 1 \%$, colorida com azul de tripano 0,05\% (Phillips e Hayman, 1970) e preservadas em lactoglicerol. A taxa de colonização foi estimada pelo método de lâmina, segundo método de GiovanETTI e Mosse (1980). Segmentos de raízes, de aproximadamente $1 \mathrm{~cm}$ de comprimento, foram avaliadas para colonização micorrízica sob microscópio óptico, sendo analisados 100 segmentos por lâmina, por repetição, por tratamento.

A dependência micorrízica (GERDEMANN, 1975) foi calculada como a diferença entre o MSPA de plantas inoculadas e não inoculadas, dividida pelas não-inoculadas, e expressa como porcentagem de MSPA de plantas inoculadas (Plenchette et al., 1983). Com base nas respostas das plantas inoculadas para produção de massa seca da parte aérea, as espécies foram arbitrariamente categorizadas em: altamente responsivas (resposta acima de $1000 \%$ sobre o controle), muito responsivas (resposta entre $500 \%$ e $999 \%$ ), responsivas (resposta entre 100 e $499 \%$ ), pouco responsivas (resposta entre $20 \%$ e $99 \%$ ), não responsivas (resposta entre $99 \%$ e $19 \%$ ) e depressivas (resposta abaixo de 19\%), segundo Zangaro FilHo et al. (2002).

A atividade da enzima fosfatase ácida foliar foi avaliada de acordo com o procedimento de BESFORD (1980). Utilizaram-se $100 \mathrm{~g}$ de limbo foliar recém coletado, os quais foram incubados em $8 \mathrm{~mL}$ de paranitrofenilfosfato (p-NPP) em tampão acetato de sódio (pH 4,0). Após incubação por 20 minutos, a 30 ${ }^{\circ} \mathrm{C}$, ao abrigo da luz, $5 \mathrm{~mL}$ da mistura foram alcalinizados com $2 \mathrm{~mL}$ de $\mathrm{NaOH}$ na concentração 2 $\mathrm{mol} \mathrm{L}^{-1}$, estimando-se colorimetricamente $(420 \mathrm{~nm})$ a quantidade de paranitrofenol formado. Os resultados foram expressos em mg p-NPP g ${ }^{-1} \mathrm{~h}^{-1}$.

Os dados de altura, massa fresca e seca de parte aérea e fosfatase ácida foram transformados empregando $\log (x+10)$ e os de colonização radicular em arc sem $\sqrt{X+0,5}$, submetidos à análise de variância e as médias comparadas pelo teste de Tukey a $1 \%$ de probabilidade.

\section{RESULTADOS E DISCUSSÃO}

Todas as variáveis analisadas exibiram diferenças significativas entre as espécies vegetais, tratamentos de inoculação de FMA e para a interação dos dois fatores (Tabela 1). As maiores alturas foram verificadas para pitangueira e goiabeira, seguidas do capixingui, porém apenas a goiabeira e o capixingui exibiram diferenças significativas entre tratamentos de inoculação, com os maiores resultados para as plantas que receberam o inóculo de FMA.

Assim como no presente para a goiabeira e o capixingui (Tabela 1), CARNEIRO et al. (2004) relataram que mudas de espécies arbóreas inoculadas com FMA tivearam maior crescimento em altura e diâmetro de caule, diferindo significativamente das plantas não inoculadas. 
Tabela 1. Altura, massa fresca de parte aérea (MFPA) e massa seca de parte aérea (MSPA) de espécies arbóreas, inoculadas ou não com fungos micorrízicos arbusculares, em condições de casa de vegetação. Média de 10 repetições

\begin{tabular}{|c|c|c|c|c|c|c|}
\hline \multirow{2}{*}{ Tratamentos } & \multicolumn{2}{|c|}{ Altura } & \multicolumn{2}{|c|}{ MFPA } & \multicolumn{2}{|c|}{ MSPA } \\
\hline & Inoculado & Não inoculado & Inoculado & Não inoculado & Inoculado & Não inoculado \\
\hline & \multicolumn{2}{|c|}{$\mathrm{cm}$} & \multicolumn{4}{|c|}{$-g-$} \\
\hline Pitangueira & $29,60 \mathrm{aA}$ & $28,40 \mathrm{aA}$ & $4,75 \mathrm{bA}$ & 3,66 aA & $1,93 \mathrm{cA}$ & $1,36 \mathrm{aA}$ \\
\hline Goiabeira & $24,00 \mathrm{aA}$ & $9,21 \mathrm{bB}$ & $11,27 \mathrm{aA}$ & $1,25 \mathrm{abB}$ & $4,21 \mathrm{aA}$ & $0,33 \mathrm{bB}$ \\
\hline Capixingui & $14,20 \mathrm{bA}$ & $7,38 \mathrm{bcB}$ & 9,65 aA & $1,03 \mathrm{bB}$ & $2,82 \mathrm{bcA}$ & $0,20 \mathrm{bB}$ \\
\hline Am. bravo & $7,34 \mathrm{cA}$ & $6,69 \mathrm{bcA}$ & $2,83 \mathrm{bA}$ & $1,05 \mathrm{bA}$ & $1,05 \mathrm{cA}$ & $0,30 \mathrm{bA}$ \\
\hline Ipê amarelo & $7,07 \mathrm{cA}$ & $4,60 \mathrm{cdA}$ & $4,27 \mathrm{bA}$ & $0,39 \mathrm{bB}$ & $1,59 \mathrm{cA}$ & $0,10 \mathrm{bB}$ \\
\hline Pororoca & $5,91 \mathrm{cA}$ & $3,43 \mathrm{dA}$ & $5,49 \mathrm{bA}$ & $0,48 \mathrm{bB}$ & $1,69 \mathrm{cA}$ & $0,18 \mathrm{bB}$ \\
\hline Esp. $x$ Inoc. & \multicolumn{2}{|c|}{$13,67^{* *}$} & \multicolumn{2}{|c|}{$14,43^{* *}$} & \multicolumn{2}{|c|}{$15,35^{* *}$} \\
\hline $\mathrm{CV}(\%)$ & \multicolumn{2}{|c|}{4,14} & \multicolumn{2}{|c|}{5,11} & \multicolumn{2}{|r|}{2,40} \\
\hline
\end{tabular}

Médias seguidas de mesma letra, minúscula na coluna e maiúscula na linha, para cada variável, não diferem pelo teste de Tukey a $1 \%$ de probabilidade ${ }^{* *}=$ significativo a $1 \%$ de probabilidade pelo teste $\mathrm{F}$. Dados foram transformados empregando log $(\mathrm{x}+10)$.

A goiabeira e o capixingui exibiram as maiores MFPA e a goiabeira os maiores MSPA, no tratamento com inoculação de FMA, enquanto a pitangueira os maiores valores para ambas as variáveis, nos tratamentos sem inoculação. Entre tratamentos de inoculação, apenas a pitangueira e o amendoim bravo não mostraram diferenças significativas para estas variáveis (Tabela 1). SANTOS (2008) relatou que, para todos os tratamentos com inoculação, o MSPA das espécies arbóreas foi maior, indicando benefício no aumento da biomassa da comunidade de plantas. Isso também foi verificado por FloRES-AYLAS et al. (2003) para espécies arbóreas em fase inicial de crescimento.

Assim como observado no presente trabalho, Schiavo e Martins (2002) não verificaram diferenças significativas entre tratamento de inoculação para MSPA, para a goiabeira, em condições de casa de vegetação. De forma contrária, KUMARAn e AzIZAH (1995) demonstraram que mudas de goiabeira inoculadas com Glomus mossae e Scutellospora calospora tiveram aumento de MSPA e maior absorção de nutrientes.

Essas diferenças relatadas, consistentemente altas e significativas entre o crescimento de plantas micorrizadas e não micorrizadas deve-se, segundo DAFT e Nicolson (1966), a dois fatores: disponibilidade de nutrientes no solo e colonização radicular. A acidez é o maior fator de degradação dos solos e suas características químicas, na disponibilidade de nutrientes, assim como, na assimilação desses nutrientes pelas plantas. $\mathrm{O} \mathrm{pH}$ no solo da área em estudo está baixo $(\mathrm{pH}=4,1)$, mesmo para uma região de Cerrado. Da mesma forma, a acidez potencial está alta $\left(\mathrm{H}+\mathrm{Al}=22,6 \mathrm{mmol}_{\mathrm{c}} \mathrm{dm}^{3}\right)$, o que pode levar a um bloqueio o crescimento radicular, possivelmente pela ausência da divisão celular (FERREIRA et al., 1997).
Essas condições de solo podem ser prejudiciais às espécies vegetais menos tolerantes e, consequentemente, interferir na colonização micorrízica.

As maiores colonizações radiculares foram detectadas para a goiabeira, o capixingui, o ipê amarelo e a pororoca, as quais podem ser consideradas muito altas, segundo ZANGARO et al. (2002), pois exibiram valores de colonização variando de $83,50 \%$ a $94,90 \%$ (Tabela 2 ). Os menores valores, considerados de média colonização, foram exibidos pela pitangueira $(41,10 \%)$.

Com resultados próximos aos verificados no presente trabalho, exceto para a pitangueira, ZANGARO FILHO et al. (2002), estudando a resposta à inoculação em espécies arbóreas nativas da bacia do rio Tibagi (PR), em condições de casa de vegetação, relataram que em capixingui e pitangueira a colonização foi muito alta; o ipê-amarelo exibiu alta colonização; a goiabeira, média colonização e o amendoim bravo, baixa colonização radicular.

Essas espécies, também, altos valores de dependência micorrízica; exemplo, a goiabeira foi altamente responsiva (Tabela 2). As demais espécies foram muito responsivas, exceto o amendoim bravo e a pitangueira responsiva e não responsiva, respectivamente.

O crescimento e a resposta das espécies arbóreas estudadas quanto à inoculação com FMA autóctones de solo de cerrado preservado, demonstram que a comunidade continha espécies fúngicas efetivas a algumas das plantas estudadas. Desta forma, a goiabeira exibiu respostas significativas entre tratamento de inoculação, mostrando elevados valores para altura, MFPA e MSPA (Tabela 1), além da dependência micorrízica (Tabelas 1 e 2). 
Tabela 2. Atividade da fosfatase ácida foliar, colonização micorrízica e dependência micorrízica das diferentes espécies arbóreas, inoculadas ou não com fungos micorrízicos arbusculares.

\begin{tabular}{|c|c|c|c|c|c|}
\hline \multirow{2}{*}{ Tratamentos } & \multicolumn{2}{|c|}{ Fosfatase } & \multicolumn{2}{|c|}{ Colonização micorrízica } & \multirow{2}{*}{$\begin{array}{c}\text { Dependência } \\
\text { micorrízica }\end{array}$} \\
\hline & Inoculado & Não inoculado & Inoculado & Não inoculado & \\
\hline & \multicolumn{2}{|c|}{$\overline{m g ~ p-N P P ~ g}{ }^{-1} h^{-1}$} & \multicolumn{2}{|c|}{$\overline{ } \%$} & \\
\hline Pitangeira & $4,04 \mathrm{abA}$ & $4,13 \mathrm{bA}$ & $41,10 \mathrm{cA}$ & $0,00 \mathrm{aB}$ & 41,15 \\
\hline Goiabeira & $2,91 \mathrm{bA}$ & $4,21 \mathrm{bA}$ & $94,90 \mathrm{aA}$ & $0,00 \mathrm{aB}$ & $1.187,95$ \\
\hline Capixingui & $5,65 \mathrm{aB}$ & $11,82 \mathrm{aA}$ & $91,40 \mathrm{aA}$ & $0,00 \mathrm{aB}$ & 591,44 \\
\hline Am. bravo & $3,52 \mathrm{abA}$ & $3,88 \mathrm{bA}$ & $66,50 \mathrm{bA}$ & $0,00 \mathrm{aB}$ & 245,42 \\
\hline Ipê amarelo & $1,44 \mathrm{cA}$ & $2,45 \mathrm{bA}$ & $94,50 \mathrm{aA}$ & $0,00 \mathrm{aB}$ & 989,54 \\
\hline Pororoca & $3,85 \mathrm{abA}$ & $4,61 \mathrm{bA}$ & $83,50 \mathrm{aA}$ & $0,00 \mathrm{aB}$ & 804,27 \\
\hline Esp. $x$ Inoc. & \multicolumn{2}{|c|}{$6,33^{* *}$} & \multicolumn{2}{|c|}{$11,88^{* *}$} & - \\
\hline $\mathrm{CV}(\%)$ & \multicolumn{2}{|c|}{3,91} & \multicolumn{2}{|c|}{5,62} & - \\
\hline
\end{tabular}

Médias (10 repetições) seguidas de mesma letra, minúscula na coluna e maiúscula na linha, para cada parâmetro, não diferem entre si pelo teste de Tukey a $1 \%$ de probabilidade. ${ }^{* *}=$ significativo a $1 \%$ de probabilidade pelo teste F. Dados de fosfatase ácida foram transformados empregando $\log (x+10)$ e os de colonização radicular em arc sen $\sqrt{\mathrm{X}+0,5}$.

Os teores de fosfatase ácida revelaram diferenças significativas entre as espécies arbóreas, entre os tratamentos de inoculação e para a interação desses fatores. Apenas o capinxigui exibiu diferenças significativas entre os tratamentos inoculados e os não- inoculados, com os valores mais elevados observados no tratamento não inoculado (Tabela 2).

A atividade da fosfatase ácida é considerada um indicador do estado nutricional das plantas, pois sua atividade aumenta à medida que se eleva a deficiência desse nutriente (AsCENCIO, 1994). O nível de fósforo no solo e a inoculação, segundo SANTOS (2008), interferem no desenvolvimento das plantas, sendo os efeitos específicos e dependentes das espécies vegetais. A absorção de nutrientes pelas plantas, especialmente de fósforo, aumentando seu desenvolvimento, pode ser associada à atividade dos FMA (Moreira e Siqueira, 2006).

Esses resultados comprovam que a eficiência da associação e a efetividade dos FMA variam em função das espécies de fungos e das espécies vegetais (JANOS, 1988). Espécies arbóreas nativas com respostas positivas à colonização de FMA, quando não inoculadas durante a formação das mudas, exibem crescimento muito reduzido após o transplante (Pouyú-Rojas e Sigueira, 2000). Esse conceito se aplica para a maioria das espécies estudadas no presente trabalho, exceto a pitangueira e o amendoim bravo, cujos menores valores para as variáveis estudadas foram encontrados no tratamento não inoculado (Tabelas 1 e 2).

A resposta à inoculação e a elevada colonização de FMA geralmente está associada às espécies de plantas e ao rápido crescimento (KoIDE, 1991). Estes autores corroboram os resultados constantes no presente trabalho, em que a Goiabeira e o Capinxigui, com rápido crescimento, foram também altamente responsivos ou muito responsivos, respectivamente. Entretanto, contrariando o autor acima citado, o Ipê-amarelo, apesar do crescimento mais lento, no presente trabalho, foi responsivo à inoculação e exibiu elevada porcentagem de colonização micorrízica (Tabela 2).

As exigências nutricionais de muitas espécies nativas ainda são pouco conhecidas, mas a presença de micorrizas vem sendo relatada em alguns casos. O efeito positivo da inoculação para o crescimento de espécies arbóreas nativas de cerrado em solo de baixa fertilidade foram relatadas por FLORES-AyLAS et al. (2003), em revegetação mista, mostrando que as micorrízicas podem ser utilizadas como importante ferramenta no preparo de mudas de espécies arbóreas nativas, em programas de inoculação, para serem usadas na revegetação e reabilitação de terras degradadas.

Como o período de seis meses empregado no presente trabalho, é relativamente curto para conclusões definitivas, recomenda-se que outros sejam realizados nesta linha de pesquisa, especialmente em campo, envolvendo maior tempo de observações e diversidade de espécies, tanto vegetal como fúngica. A maioria das espécies utilizadas no estudo pode ser utilizada em projetos de paisagismo ou são frutíferas (atraindo pássaros e insetos), e podem ser indicadas, segundo Lorenzi (2002), para programas de revegetação de áreas degradadas e de preservação permanente. 


\section{CONCLUSÃO}

A goiabeira e o capixingui, seguidos pelo ipê amarelo e pororoca, são de alta colonização radicular e altamente ou muito responsivos à micorrização, $\mathrm{o}$ que sugere seu potencial em projetos de revegetação no cerrado brasileiro ou no enriquecimento de áreas degradadas.

\section{REFERÊNCIAS}

ASCENCIO, J. Acid phosphatase as a diagnostic tool. Communications in Soil Science and Plant Analyses, v.25, p.1553-1564, 1994.

BESFORD, R.T. A rapid tissue test for diagnosing phosphorus deficiency in the tomato plant. Annals of Botany, v.45, p.225227,1980 .

CARNEIRO, M.A.C.; SIQUEIRA, J.O.; DAVIDE, A.C. Fósforo e inoculação com fungos micorrízicos arbusculares no estabelecimento de mudas de embaúba (Cecropia pachystachya Trec.). Pesquisa Agropecuária Tropical, v.34, p.119-125, 2004.

CARNEIRO, M.A.C.; SIQUEIRA, J.O.; DAVIDE, A.C.; GOMES, L.J.; CURI, N.; DO VALE, F.R. Fungos micorrízicos e superfosfato no crescimento de espécies arbóreas tropicais. Scientia Forestalis, v.50, p.21-36, 1996.

DAFT, M.J.; NICOLSON, T.H. Effect of Endogone mycorrhiza on plant growth. New Phytologist, v.65, p.343-350, 1966.

DUFF, S.M.G.; SARATH, G.; PLAXTON, W.C. The role of acid phosphatases in plant phosphorus metabolism. Plant Physiology, v.90, p.791-800, 1994.

EMPRESA BRASILEIRA DE PESQUISA AGROPECUÁRIA (Embrapa). Sistema brasileiro de classificação de solo. Rio de Janeiro: Embrapa Solos. 1999. 412p.

FARIA, S.M.; CHADA, S.S. Interação microrganismos e plantas na recuperação de áreas degradadas. Disponível em: www.rc.unesp.br/xivsbsp/mesa03MSMF.pdf. Acesso em 25 mar 2007.

FERREIRA, C.A.G.; FUSER, J.E.; ZANATTA, P.R.;. WILLIAMS, D.D. Reabilitação de áreas mineradas de bauxita no planalto de Poços de Caldas, MG. In: SIMPOSIO BRASILEIRO DE RECUPERAÇÃO DE ÁREAS DEGRADADAS, 3., Ouro Preto, 1997. Anais... Viçosa, MG: SOBRADE/UFV-DPS/DEF, 1997. p.27-35.

FLORES-AYLAS, W.W.;SAGGIN JÚNIOR, O.J.; SIQUEIRA, J.O.; DAVIDE, A.C. Efeito de Glomus etunicatum e fósforo no crescimento inicial de espécies arbóreas em semeadura direta. Pesquisa Agropecúaria Brasileira, v.38, p.257-266, 2003.

GARCIA, M.; ASCENCIO, J. Root morphology and acid phosphatase activity in tomato plants during development of and recovery from phosphorus stress. Journal of Plant Nutrition, v.15, p.2491-2503, 1992.
GERDEMANN, J.W. Vesicular-arbuscular mycorhiza. In: TORREY, J.G.; CLARKSON, D.T. (Eds.). The development and function of root. New York: Academic Press, 1975. p.575-591.

GERDEMANN, J.W.; NICOLSON, T.H. Spores of mycorrhizal Endogone species extracted from soil by wet sieving and decanting. Transaction of British Mycology Society, v.46, p.234-244, 1963.

GIOVANETTI, M.; MOSSE, B. An evaluation of techniques for measuring vesicular arbuscular mycorrhizal infection in roots. New Phytologist, v.84, p.489-500, 1980.

JAKOBSEN, I. Transport of phosphorus and carbon in VA Mycorrhizas. In: VARMA, A.; HOCK, B. (Ed.). Mycorrhiza: structure, function, molecular biology and biotechnology. Berlin: Springer-Verlag, 1995. p.297-324.

JANOS, D.P. Mycorrhiza applications in tropical forestry are temperate-zone approaches appropriates? In.: NG, F.S.P. (Ed.). Trees and mycorrhiza. Kuala Lumpur: Forest Research Institute, 1988. p.133-188.

JENKINS, W.R. A rapid centrifugal-flotation technique for separating nematodes from soil. Plant Disease Reporter, v.48, p.692, 1964.

KOIDE, R.T. Nutrient supply, nutrient demand and plant response to mycorrhizal infection. New Phytologist, v.117, p.365-386, 1991

KUMARAN, S.; AZIZAH, H. C. Influence of biological soil conditioner on mycorrhizal versus non - mycorrhizal guava seedlings. Tropical Agriculture, v.72, p. 39-43, 1995.

LORENZI, H. Árvores brasileiras: manual de identificação e cultivo de plantas arbóreas do Brasil. 4 ed. v.1. Nova Odessa: São Paulo; Instituto Plantarum, 2002. 352p.

MENDES FILHO, P.F. Potencial de reabilitação do solo de uma área degradada, através da revegetação e do manejo microbiano. 2004. 105f . Tese (Doutorado em Agronomia Solos e Nutrição de Plantas) - Escola Superior de Agriculatura "Luiz de Queiroz" /Universidade de São Paulo. Piracicaba.

MOREIRA, F.M.S.; SIQUEIRA, J.O. Micorriza. Microbiologia e bioquímica do solo. 2 ed. Lavras: Universidade Federal de Lavras, 2006. p.543-716.

PHILLIPS, J.M.; HAYMAN, D.S. Improved procedures for clearing roots for rapid assessment of infection. Transaction of British Mycology Society, v.55, p.158-161, 1970.

PLENCHETTE, C.; FORTIN, J.A.; FURLAN, V. Growth response of several plants species to mycorrhiza in a soil of moderate P fertility. I. Mycorrhizal dependency under field conditions. Plant and Soil, v.70, p.191-209, 1983.

POUYÚ-ROJAS, E.; SIQUEIRA, J.O. Micorriza arbuscular e fertilização do solo no desenvolvimento pós-transplante de mudas de sete espécies florestais. Pesquisa Agropecuária Brasileira, v.35, p.103-114, 2000. 
RAIJ, B.V.; QUAGGIO, J.A. Métodos de análise de solos para fins de fertilidade. Campinas: Instituto Agronômico. 1983. 31p. (Boletim Técnico, 81)

SANDERS, I.R.; CLAPP, J.P.; WIEMKEN, A. The genetic diversity of arbuscular mycorrhizal fungi in natural ecosystems - a key to understanding the ecology and functioning of the mycorrhizal symbiosis. New Phytologist, v.133, p.123-134, 1996.

SANTOS, J.G.D. Riqueza dos fungos micorrízicos arbusculares no solo e o crescimento inicial de espécies arbóreas nativas. 2008. 80f. Tese (Doutorado em Microbiologia Agrícola) Universidade Federal de Lavras. Lavras.

SCHERER, A.; COLOZZI-FILHO, A.; ANDRADE, D.S.; TAVARES-FILHO, J. Biomassa microbiana e micorrizas arbusculares em agrossistema café orgânico arborizado. In: FERTBIO2004. Lages, 2004. Anais... Lages-SC: UDESC; SBCS, 2004. (CD-Rom)

SCHIAVO, J.A.; MARTINS, M.A. Produção de mudas de goiabeira (Psidium guajava L.), inoculadas com fungo micorrízico arbuscular Glomus clarum, em substrato agroindustrial. Revista Brasileira de Fruticultura, v.24, p.519$523,2002$.

ZANGARO FILHO, W.; NISIZAKI, S.M.A.; DOMINGOS, J.C.B.; NAKANO, E.M. Micorriza arbuscular em espécies arbóreas nativas da Bacia do Rio Tibagi, Paraná. Cerne, v.8, p.77-87, 2002. 